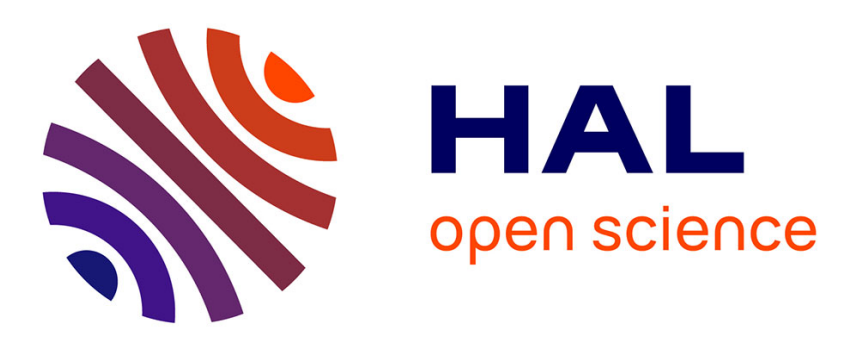

\title{
The Ouzo effect to selectively assemble molybdenum clusters into nanomarbles or nanocapsules with increased HER activity
}

Flavien Sciortino, Jérôme Cuny, Fabien Grasset, Corinne Lagrost, P. Lemoine, Alain Moréac, Yann Molard, Toshiaki Takei, Stéphane Cordier, Soizic

Chevance, et al.

\section{To cite this version:}

Flavien Sciortino, Jérôme Cuny, Fabien Grasset, Corinne Lagrost, P. Lemoine, et al.. The Ouzo effect to selectively assemble molybdenum clusters into nanomarbles or nanocapsules with increased HER activity. Chemical Communications, 2018, 54 (95), pp.13387-13390. 10.1039/C8CC07402J . hal-01946522

\section{HAL Id: hal-01946522 \\ https://hal.science/hal-01946522}

Submitted on 4 Mar 2019

HAL is a multi-disciplinary open access archive for the deposit and dissemination of scientific research documents, whether they are published or not. The documents may come from teaching and research institutions in France or abroad, or from public or private research centers.
L'archive ouverte pluridisciplinaire $\mathbf{H A L}$, est destinée au dépôt et à la diffusion de documents scientifiques de niveau recherche, publiés ou non, émanant des établissements d'enseignement et de recherche français ou étrangers, des laboratoires publics ou privés. 


\title{
The Ouzo Effect to Selectively Assemble Molybdenum Clusters into Nanomarbles or Nanocapsules with Increased HER Activity
}

\author{
Flavien Sciortino ${ }^{\mathrm{a}}$, Jérôme Cuny ${ }^{\mathrm{b}}$, Fabien Grasset ${ }^{\mathrm{c}}$, Corinne Lagrost ${ }^{\mathrm{a}}$, Pierric Lemoine ${ }^{\mathrm{a}}$, Alain \\ Moréac $^{\mathrm{d}}$, Yann Molard ${ }^{\mathrm{a}}$, Toshiaki Takei ${ }^{\mathrm{e}}$, Stéphane Cordier ${ }^{\mathrm{a}}$, Soizic Chevance ${ }^{\mathrm{a}}$, Fabienne Gauffre* ${ }^{*}$
}

Metal clusters Nanoparticles are obtained by a simple solvent shifting procedure called the Ouzo effect. Remarkably, the assembly of $\left[\left\{\mathrm{Mo}_{6} \mathrm{Br}_{8}\right\} \mathrm{L}_{6}\right]^{2-}$ ( $\mathrm{L}=\mathrm{Br}^{-}$or $\mathrm{NCS}^{-}$) cluster units can be directed into nanomarbles or nanocapsules depnding on the cluster chemistry. Deposited on electrodes, the nanoparticles show good activities in electrochemical water splitting in mild conditions.

With their dimensions in the nanometer range, metal atom clusters hold an intermediate position between molecules and nanoparticles. They offer a vast compositional and structural diversity, and among all possible structures, the octahedral molybdenum cluster units $\left[\left\{\mathrm{Mo}_{6} \mathrm{X}_{8}\right\} \mathrm{L}_{6}\right]^{2-}$ (where $\mathrm{X}$ are inner halide ligands and $\mathrm{L}$ are apical anionic organic or inorganic ligands) have been the most investigated moieties, owing to their photophysical properties as well as their catalytic performances in water splitting. ${ }^{1-9}$ Furthermore, in the broad context of nanoarchitectonics ${ }^{10-13}$ and in view of potential applications in catalysis, nanomedicine, or as building blocks to elaborate porous materials ${ }^{14,15}$ considerable efforts have been devoted to the integration of $\left[\left\{\mathrm{Mo}_{6} \mathrm{X}_{8}\right\} \mathrm{L}_{6}\right]^{2-}$ cluster units into silica or polymer particles. ${ }^{3,16-19}$ However, the elaboration of nanomaterials exclusively from clusters was considered only very recently. ${ }^{20}$

Nanoprecipitation by solvent shifting is the most straightforward strategy to obtain nanoparticles, widely used in pharmacy to produce nanoparticulate drugs. ${ }^{21}$ The elaboration of nanocapsules is more challenging although it provides interesting opportunities resulting from their internal cavity, with potential applications in catalysis, photonics, enzyme protection or drug carriers. ${ }^{22,23}$ Generally, inorganic capsules are formed by adsorption of the inorganic material on a solid or molecular template. ${ }^{11,24}$ Very recently, we demonstrated that under solvent shifting conditions, small $(\sim 5 \mathrm{~nm})$ hydrophobic nanoparticles stabilize liquid/liquid interfaces in mixtures of water and THF, forming liquid droplets coated by nanoparticles. ${ }^{25,26}$ This phenomenon, related to the Ouzo effect ${ }^{27}$ (i.e. a spontaneous emulsification occurring in miscible solvent/water mixtures in presence of

\footnotetext{
Univ Rennes, CNRS, ISCR-UMR6226, SCANMat-UMS2001, F-35000 Rennes, France.

b. Laboratoire de Chimie et Physique Quantiques, IRSAMC, Université Paul Sabatier, 118 Route de Narbonne, 31062 Toulouse Cedex 4, France.

CNRS, LINK (Laboratory for Innovative Key Materials and Structures)-UMI3629, National Institute for Materials Science (NIMS), 1-1 Namiki, Tsukuba 305-0044, Japan

d. Univ Rennes, CNRS, IPR-UMR6251, F-35000 Rennes, France

e. International Center for Materials Nanoarchitectonics, MANA, National Institute

of Material Science (NIMS), 1-1 Namiki, Tsukuba 305-0044, Japan
}

hydrophobic impurities), was used to produce nanocapsules with a crosslinked nanoparticle-polymer shell. ${ }^{25,26}$ Following this simple solvent shifting strategy, we herein elaborated "nanocapsules" (hollow nanoparticles) and "nanomarbles" (solid nanoparticles) solely composed of molybdenum clusters. We found that nanocapsules but also nanomarbles can be obtained in a well-controlled fashion, depending on the solubility of the initial cluster compound. The chemical structure of the resulting material was thoroughly investigated using Energy Dispersive X-ray Spectroscopy (EDS) and Raman spectroscopy combined with quantum chemical calculations. The mechanism of capsule formation is analyzed using dynamic light scattering (DLS) and transmission electron microscopy (TEM). In addition, the cluster-based nanoparticles show interesting electrocatalytic efficiency towards hydrogen evolution reaction (HER) in mild aqueous conditions.

Based on our previous work, ${ }^{25}$ we induced the self-assembly of $\mathrm{Cs}_{2}\left[\mathrm{Mo}_{6} \mathrm{Br}_{14}\right]$ (cluster compound $\underline{1}$ ) and $\left(\mathrm{NH}_{4}\right)_{2}\left[\mathrm{Mo}_{6} \mathrm{Br}_{8} \mathrm{NCS}_{6}\right]$ (cluster compound 2) via solvent shifting from THF to water. In a typical procedure, water is rapidly added to a $1 \mathrm{mM}$ suspension of cluster dispersed in THF to reach a $(80: 20)$ water:THF ratio. The mixture is let to mature for $24 \mathrm{~h}$ and then heated at $40^{\circ} \mathrm{C}$ in open vial for $15 \mathrm{~h}$. Nanomarbles of ca $100 \mathrm{~nm}$ are obtained from $\underline{1}$ (Figure 1a), whereas $\underline{2}$ yields nanocapsules (Figure 1b). Interestingly, the capsules can swell and eventually blow up when heated in open vials, due to the building of internal pressure from solvent vaporization (insert Figure 1b).

High Resolution TEM (HRTEM) (Figure 2) and Selected Area Electron Diffraction (SAED) analyses (Figure SI-1) clearly evidence the amorphous state of both structures. Chemical mapping analysis by EDS (Figure 2) shows that $\mathrm{Mo}, \mathrm{Br}$ and $\mathrm{O}$ are co-localized and uniformly distributed within the nanomarbles. This strongly suggests the substitution of apical ligands by hydroxyl groups or water molecules, as was previously described. ${ }^{28}$ The substitution is confirmed by some $\mathrm{H}_{2}\left[\mathrm{Mo}_{6} \mathrm{Br}_{8}^{\mathrm{i}}(\mathrm{OH})_{6}^{\mathrm{a}}\right] \cdot 12 \mathrm{H}_{2} \mathrm{O}$ crystals growing in solution during the self-assembly of $\underline{1}$ (see Figure SI-2, Tables SI- 1 and SI-2 for single crystal X-ray diffraction analysis (XRD)). In contrast, the oxygen signal is relatively weak for the nanocapsules, indicating lower oxygen content compared to the nanomarbles, and no formation of crystal is observed. Note that the presence of oxygen may also be attributed to residual water molecules in the nanocapsules. 

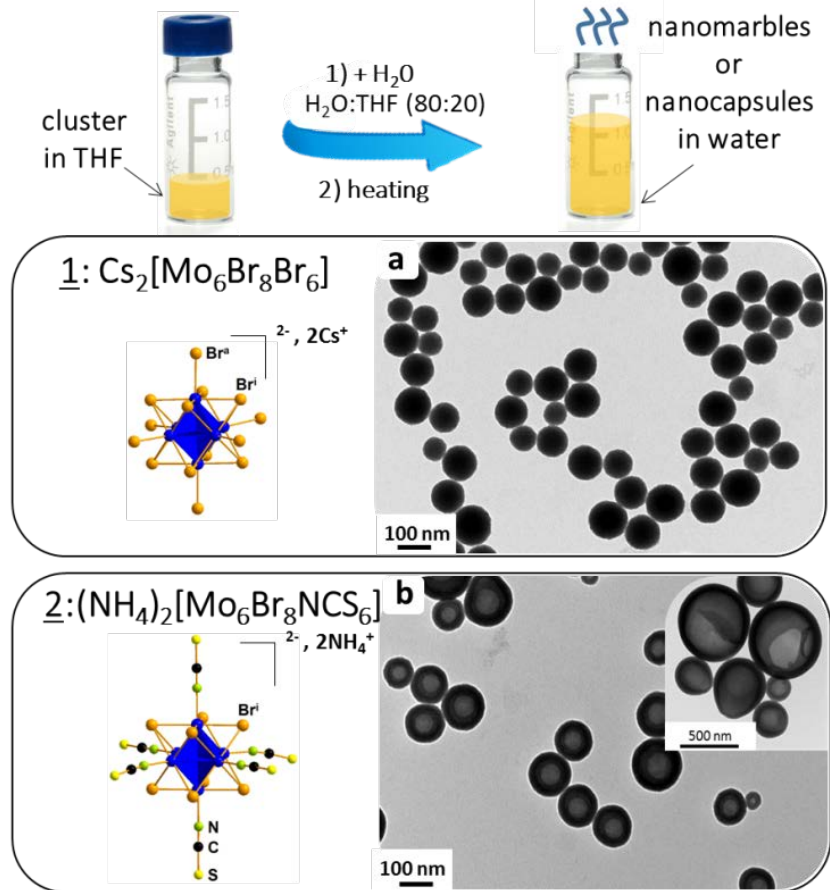

Figure 1: Elaboration of nanoassemblies via the solvent-shifting process. Definition and representation of the chemical structure of cluster compounds $\underline{1}$ and $\underline{2}$ and TEM micrographs of: (a) nanomarbles and (b) nanocapsules (Insert: nanocapsules after blow-up).

The Raman analysis of the nanomarbles and nanocapsules in comparison with that of the pristine precursors $\underline{1}$ and $\underline{2}$ and of the aquahydroxo crystal $\mathrm{H}_{2}\left[\mathrm{Mo}_{6} \mathrm{Br}_{8}^{\mathrm{i}}(\mathrm{OH})_{6}^{\mathrm{a}}\right] \cdot 12 \mathrm{H}_{2} \mathrm{O}$ (Figure 3) proved to be very effective in understanding the structure of those species (see the Supporting Information for full details). Indeed, in cluster compound $\underline{1}$, two bands (highlighted with symbol "o") associated to the vibrations of the $\mathrm{Mo}-\mathrm{Br}^{\mathrm{a}}$ bonds are observed at $149 \mathrm{~cm}^{-1}$ (stretching $\mathrm{A}_{1 \mathrm{~g}}$ ) and $256 \mathrm{~cm}^{-1}$ (stretching $E_{g}$ ). As expected, these bands are absent in the aquahydroxo crystal and in $\underline{2}$. Interestingly, they are also absent in the nanomarbles, which is a clear proof of the substitution of the apical $\mathrm{Br}^{-}$ligands during their synthesis. In the $100-400 \mathrm{~cm}^{-1}$ range, the Raman spectra of the aquahydroxo crystal and of the nanomarbles are otherwise
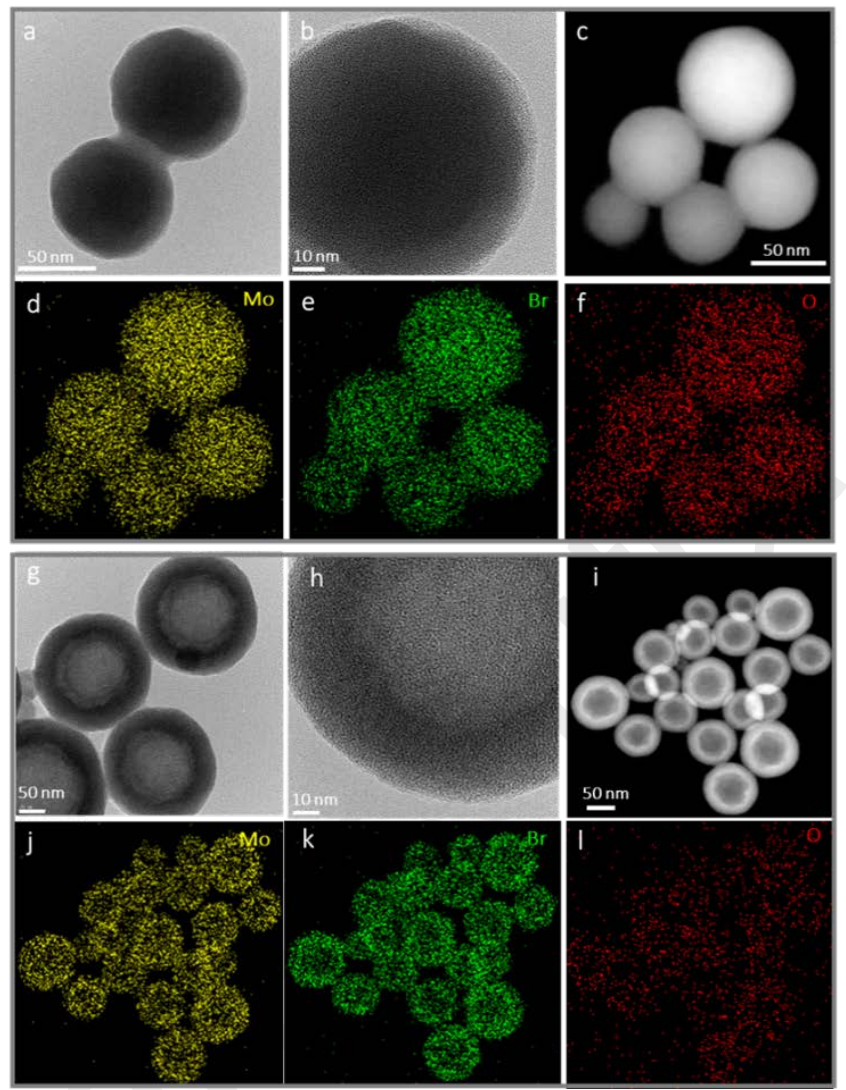

Figure 2: HRTEM micrographs (a;b) and STEM-EDS elemental mapping ( $\mathrm{Mo}, \mathrm{Br}$ and $\mathrm{O}$ ) (c-f) of nanomarbles prepared from 1. HRTEM micrographs (g;h), and STEM-EDS elemental mapping (i-I) of nanocapsules prepared from $\underline{2}$.

almost identical, highlighting the similarity of their $\left\{\mathrm{Mo}_{6} \mathrm{Br}_{8}^{i}\right\}^{4+}$ cluster cores. Those compounds share other common features at higher wavenumbers. Indeed, they both display bands at 520,880 and $930 \mathrm{~cm}^{-1}$ (highlighted with symbol "*”) that are characteristic of a bonding pattern involving hydroxo ligands. Indeed, based on quantum chemical calculations performed on an isolated dimer of $\left[\mathrm{Mo}_{6} \mathrm{Br}_{8}^{i}(\mathrm{OH})_{6}^{\mathrm{a}}\right]^{2-}$ cluster units, the band at $520 \mathrm{~cm}^{-1}$ can be attributed to the Mo-O stretching mode while the two signals at 880 and $930 \mathrm{~cm}^{-1}$ originate from the Mo-O-H bending modes in $\mathrm{Mo}-\mathrm{OH}-\mathrm{-OH}-\mathrm{Mo}$ motifs that are responsible for the binding between the two $\left[\mathrm{Mo}_{6} \mathrm{Br}_{8}^{\mathrm{i}}(\mathrm{OH})_{6}^{\mathrm{a}}\right]^{2-}$ clusters units. This demonstrates that the bonding patterns in the nanomarbles and the aquahydroxo crystal are identical. The Raman spectra of the nanocapsules and nanomarbles are different, suggesting that complete hydrolysis does not occur during nanocapsules synthesis. In these latter, vibration modes of the isothiocyanate groups (highlighted with symbol "\#") are observed in the $470-490 \mathrm{~cm}^{-1}$ range $\left(T_{2 \mathrm{~g}} \mathrm{NCS}\right.$ bending mode) and as three intense bands at 829,839 and $848 \mathrm{~cm}^{-1}$ (attributed to the $A_{1 g}$ and Eg NC-S stretching modes). From quantum calculations, no well-defined Mo-NCS stretching mode exist as it is mixed with Mo-Mo vibrations within the two experimental bands at 301 (very strong, asym) and $353 \mathrm{~cm}^{-1}$ (very strong, sym). Below $250 \mathrm{~cm}^{-1}$ the spectra of $\underline{2}$ and of nanocapsules are similar and compare well with that of $\underline{1}$, owing to similar $\left\{\mathrm{Mo}_{6} \mathrm{Br}_{8}^{\mathrm{i}}\right\}^{4+}$ cluster cores. However, a significant amount of mixing with the thiocyanate modes 

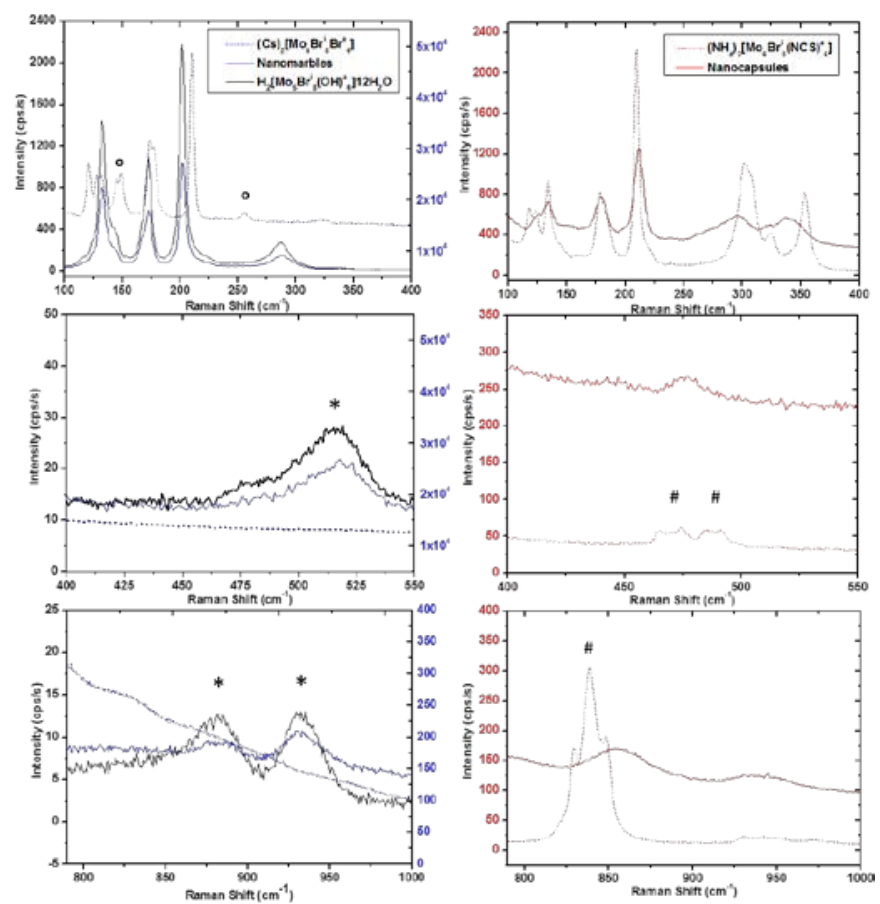

Figure 3: Raman spectra of cluster compound $\underline{1}$ (dotted blue), nanomarbles (blue solid line), and $\mathrm{H}_{2}\left[\mathrm{Mo}_{6} \mathrm{Br}_{8}^{\mathrm{i}}(\mathrm{OH})_{6}^{\mathrm{a}}\right] \cdot 12 \mathrm{H}_{2} \mathrm{O}$ crystal (black solid line), cluster compound $\underline{2}$ (dotted red) and nanocapsules (red solid line). The symbols highlight some vibrations associated to $\mathrm{Mo}-\mathrm{Br}^{\mathrm{a}}$ (o); $\mathrm{Mo}-\mathrm{O}$ or $\mathrm{Mo-}-\mathrm{OH}---\mathrm{OH}-\mathrm{Mo}\left({ }^{*}\right)$; and -NCS (\#).

occurs, particularly at $210 \mathrm{~cm}^{-1}$.

In the nanocapsules, the bands observed in the $250-400 \mathrm{~cm}^{-1}$ range are much wider than for $\underline{2}$. The strong decay of the NC-S stretching modes $\left(829-850 \mathrm{~cm}^{-1}\right)$ is another striking feature of the Raman spectra of the nanocapsules. In addition, the signal characteristic of the Mo-O stretching calculated at $520 \mathrm{~cm}^{-1}$ in $\left[\mathrm{Mo}_{6} \mathrm{Br}_{8}^{\mathrm{i}}(\mathrm{OH})_{6}^{\mathrm{a}}\right]^{2-}$ (the same vibration is calculated at $534 \mathrm{~cm}^{-1}$ in a $\left[\mathrm{Mo}_{6} \mathrm{Br}_{8}^{i}(\mathrm{NCS})_{5}^{\mathrm{a}}(\mathrm{OH})\right]^{2-}$ motif) is not observed. These results suggest a very limited hydrolysis of the $\left[\mathrm{Mo}_{6} \mathrm{Br}_{8}^{\mathrm{i}}(\mathrm{NCS})_{6}^{\mathrm{a}}\right]^{2-}$ motifs, if any. The spectral broadening of the vibrations associated to the thiocyanate groups in the nanocapsules most probably results from a distribution of chemical environments.

The hexamolybdenum clusters typically emit phosphorescence in the red or NIR window due to triplet excited state, with a wavelength sensitive to the chemical nature of the apical ligands. ${ }^{[29]}$ Figure SI-4 shows the blue-shift of the emission maximum of the cluster during the synthesis of the nanomarbles from 1 (water:THF (80:20), RT), which can be attributed to the hydrolysis of the apical ligands. ${ }^{19,30}$ The kinetics of the shift is nicely fitted by an exponential decay law, yielding a characteristic time of ca $6 \mathrm{~h}$ (Figure 4a, insert). In contrast, for compound $\underline{2}$ no shift of the emission maximum was observed over 24 hours, which suggests slow hydrolysis. In a previous study, the hydrolysis of the iodide analogous cluster unit $\left[\mathrm{Mo}_{6} \mathrm{I}_{8}(\mathrm{NCS})_{6}\right]^{2-}$ into mono-hydroxy derivatives was observed but with a very slow kinetics. ${ }^{30}$ In line with those results, the formation of $\mathrm{H}_{2}\left[\mathrm{Mo}_{6} \mathrm{Br}_{8}^{i}(\mathrm{OH})_{6}^{a}\right] \cdot 12 \mathrm{H}_{2} \mathrm{O}$ crystals was also not observed in the case of cluster compound $\underline{2}$. Although aqua ligands were reported to strongly quench the cluster luminescence due to non-radiative energy dissipation through vibrations of $\mathrm{O}-\mathrm{H}$ bonds, for both clusters we observed no more than $40 \%$ of intensity loss compared to the pristine cluster compounds in THF. Besides phosphorescence emission, the cluster nanoassemblies also generated singlet oxygen $\left(\mathrm{O}_{2}\right.$ $\left.\left({ }^{1} \Delta \mathrm{g}\right)\right)$ via photosensitization from the triplet excited state (Figure SI- 5).

The mechanism of formation of the nanocapsules was investigated in details by TEM and DLS (see Supp. Info.) and proceeds through two steps. (1) In water:THF mixtures, the cluster units $\underline{2}$ rapidly adsorb at liquid/liquid interfaces, which stabilizes solvent droplets formed by Ouzo effect. Dissolved clusters and dense aggregates are also present in equilibrium with adsorbed clusters, enabling size focusing of the droplets. (2) Later on, the free species also feed the thickening of the shell. Indeed, the wall of the capsule, which is initially less than a few nanometers thick, growths to over 20nm (Fig SI-7). With time, the dispersion in the size of the capsules and in wall thickness increases (Fig SI-7d and e). The selection between capsules and spheres seems to depend on the water solubility of the clusters. Indeed, compound $\underline{1}$ is relatively poorly soluble in water and, upon addition of water, phase separates into dense nanoparticles as in conventional nanoprecipitation. In contrast, $\underline{2}$ has more affinity for water and remains mostly in solution in the water:THF mixture, whereas a small fraction of clusters adsorbs at the interface. These will later serve as nucleation sites for the growth of the capsule shell.

Electrochemical water splitting is one of the most promising ways to store sustainable energy resources. It proceeds through two half-cell reactions: the reduction of protons at the cathode (HER for Hydrogen Evolution Reaction) and the oxidation of water at the anode (OER for Oxygen Evolution Reaction) and generally requires expensive noble-metal catalysts operating in acidic or alkaline conditions, causing corrosion issues. ${ }^{31}$ Molecular catalysts can be produced at lower costs, but it is generally necessary to immobilize them on a solid electrode. Feliz et al. have recently proved that $\left[\mathrm{Mo}_{6} \mathrm{Br}_{8}{ }_{8}(\mathrm{OH})_{6}^{\mathrm{a}}\right]^{2-}$ units show catalytic activity toward HER. ${ }^{32}$ Until now, only few studies reported molecular catalysts operating in neutral conditions. ${ }^{33}$ In this context, the construction of nanoassemblies made from metal clusters may present a true advantage. The nanoassemblies were dropcasted over a glassy carbon electrode (GCE) and their electrocatalytic response was compared to that of bare GCE and of pristine cluster compounds $\underline{1}$ and $\underline{2}$ deposited onto GCE (Figure 4) at pH 7 . The nanomarbles/GCE and nanocapsules/GCE yield greater HER activity in comparison to bare GCE and to clusters compounds deposited on GCE. 

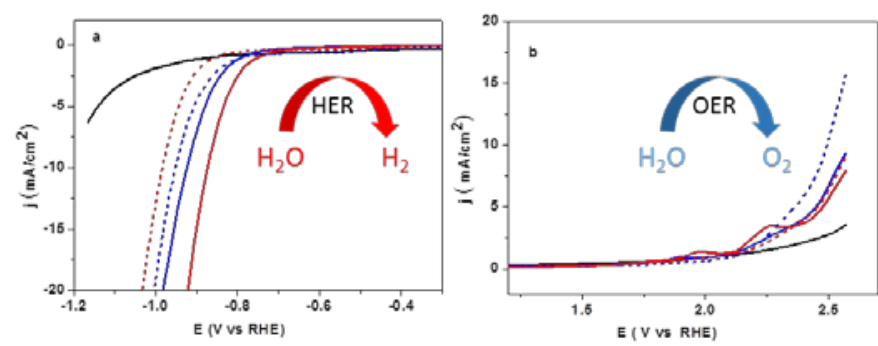

Figure 4: Polarization curves for bare GCE (black), for GCE supporting nanomarbles (blue), cluster $\underline{1}$ (dashed blue), nanocapsules (red) and cluster $\underline{2}$ (dashed red) in Arpurged $1 \mathrm{M} \mathrm{KNO}_{3} \mathrm{pH} 7$ solution, (a) HER (b) OER

In contrast to the bare GCE, the benchmark current densities of $10 \mathrm{~mA} / \mathrm{cm}^{2}$ are readily reached for potentials equal to ca $0.95 \mathrm{~V}$ for all cluster species (Figure 4a). This corresponds to an overpotential of approximately $500 \mathrm{mV}$, which is very promising compared to the overpotentials reported for molecular catalysts in neutral media. ${ }^{33}$ Remarkably, the reduction potential is $100 \mathrm{mV}$ positively shifted for the nanocapsules compared to $\underline{2}$. Despite relatively poor OER electroactivity, all clusters species promote the oxidation of water into $\mathrm{O}_{2}$ with higher current densities in comparison to the bare GCE (Figure $\mathbf{4 b}$ ).

In conclusion, nanoparticles containing exclusively molybdenum clusters were obtained by solvent shifting. Nanomarbles vs nanocapsules can be selectively obtained by an appropriate choice of the cluster: the more hydrophobic species $\mathrm{Cs}_{2}\left[\mathrm{Mo}_{6} \mathrm{Br}_{8}^{i} \mathrm{Br}_{6}^{\mathrm{a}}\right]$ precipitates in the solvent phase, whereas the more polar compound $\left(\mathrm{NH}_{4}\right)_{2}\left[\mathrm{Mo}_{6} \mathrm{Br}_{8}^{\mathrm{i}}(\mathrm{NCS})_{6}^{\mathrm{a}}\right]$ adsorbs at interfaces, stabilizing solvent rich droplets. The chemical analysis using EDS and Raman spectroscopy combined to quantum chemical calculations clearly indicates a complete hydrolysis of the apical ligands in the case of $\mathrm{Cs}_{2}\left[\mathrm{Mo}_{6} \mathrm{Br}_{8}{ }_{8} \mathrm{Br}_{6}^{\mathrm{a}}{ }_{6}\right]$. In contrast, the hydrolysis of $\left(\mathrm{NH}_{4}\right)_{2}\left[\mathrm{Mo}_{6} \mathrm{Br}_{8}^{\mathrm{i}}(\mathrm{NCS})_{6}^{\mathrm{a}}\right]$ is not observed, but cannot be totally ruled out. Through this work, we generalize the selfassembling strategy based on the "Ouzo effect" to form nanocapsules from nanoscale inorganic compounds. Both nanomarbles and nanocapsules show interesting electrocatalytic activity toward water splitting in mild conditions. Particularly, shaping the cluster into nanocapsules enhances significantly the HER.

\section{Aknowledgement}

The authors thank ScanMat platforms, THEMIS (TEM), SIR (Raman) and Caphter (luminescence) and also C. Roiland. Thierry Roisnel from CDIFX is acknowledged for his help for single crystal X-ray diffraction data collection and V. Garcia for graphical 3D simulations. This project was initiated by F.S.

\section{Notes and references}

1 R. Ramirez-Tagle, R. Arratia-Pérez, Chem. Phys. Lett., 2008, 460, 438.

2 K. Kirakci, P. Kubát, M. Dušek, K. Fejfarová, V. Šícha, J. Jiří, K. Lang, Eur. J. Inorg. Chem., 2012, 19, 3107.

3 C. Neaime, M. Amela-Cortes, F. Grasset, Y. Molard, S. Cordier, B. Dierre, M. Mortier, T. Takei, K. Takahashi, H. Haneda, et al., Phys. Chem. Chem. Phys., 2016, 18, 30166.

4 S. Akagi, S. Fujii, N. Kitamura, Dalton Trans., 2018, 47, 1131.

5 K. Costuas, A. Garreau, et al., Phys. Chem. Chem. Phys., 2015, 17,28574

6 C. G. Morales-Guio, X. Hu, Acc. Chem. Res., 2014, 47, 2671.

7 N. A. Vorotnikova, Y. A. Vorotnikov, et al., Inorg. Chem., 2018, 57, 811.

8 D. V. Evtushok, N. A. Vorotnikova, et al., New J. Chem., 2017, 41, 14855 .

9 D. V. Evtushok, A. R. Melnikov, et al., Dalton Trans., 2017, 46, 11738.

10 P. Bauduin, S. Prevost, P. Farràs, F. Teixidor, O. Diat, T. Zemb, Angew. Chem. Int. Ed., 2011, 50, 5298.

11 K. L. Thompson, M. Williams, S. P. Armes, J. Colloid Interface Sci., 2015, 447, 217.

12 S. Cordier, F. Grasset, Y. Molard, M. Amela-Cortes, R. Boukherroub, S. Ravaine, M. Mortier, N. Ohashi, N. Saito, H. Haneda, J. Inorg. Organomet. Polym. Mater., 2015, 25, 189.

13 Y. Molard, Acc. Chem. Res., 2016, 49, 1514.

14 B. Yan, H. Zhou, A. Lachgar, Inorg. Chem., 2003, 42, 8818.

15 M. A. Moussawi, N. Leclerc-Laronze, et al., J. Am. Chem. Soc., 2017, 139, 12793.

16 A. O. Solovieva, Y. A. Vorotnikov, et al., J. Mater. Chem. B, 2016, 4, 4839.

17 N. A. Vorotnikova, M. V. Edeleva, O. G. Kurskaya, K. A. Brylev, A. M. Shestopalov, Y. V. Mironov, A. J. Sutherland, O. A. Efremova, M. A. Shestopalov, Polym. Int., 2017, 66, 1906.

18 K. Kirakci, V. Šícha, J. Holub, P. Kubát, K. Lang, Inorg. Chem., 2014, 53, 13012.

19 E. V. Svezhentseva, A. O. Solovieva, et al., New J. Chem., 2017, 41, 1670

20 K. Kirakci, J. Zelenka, M. Rumlová, J. Martinčík, M. Nikl, T. Ruml, K. Lang, J. Mater. Chem. B, 2018, 6, 4301.

21 E. Lepeltier, C. Bourgaux, P. Couvreur, Adv. Drug Deliv. Rev., 2014, 71, 86.

22 L. Leclercq, A. Mouret, S. Renaudineau, V. Schmitt, A. Proust, V. Nardello-Rataj, J. Phys. Chem. B, 2015, 119, 6326.

23 A. Prasetyanto, A. Bertucci, D. Septiadi, R. Corradini, P. Castro-Hartmann, L. De Cola, Angew. Chem. Int. Ed., 2015, 55, 3323.

24 B. Naskar, O. Diat, V. Nardello-Rataj, P. Bauduin, J. Phys. Chem. C, 2015, 119, 20985.

25 F. Sciortino, G. Casterou, P.-A. Eliat, M.-B. Troadec, C. Gaillard, S. Chevance, M. L. Kahn, F. Gauffre, ChemNanoMat, 2016, 2, 796.

26 F. Sciortino, M. Thivolle, M. L. Kahn, C. Gaillard, S. Chevance, F. Gauffre, Soft Matter, 2017, 13, 4393.

27 F. Ganachaud, J. L. Katz, ChemPhysChem, 2005, 6, 209.

28 T. Aubert, A. Burel, M.-A. Esnault, S. Cordier, F. Grasset, F. Cabello-Hurtado, J. Hazard. Mater., 2012, 219-220, 111.

29 K. Kirakci, P. Kubát, J. Langmaier, T. Polívka, M. Fuciman, K. Fejfarová, K. Lang, Dalton Trans., 2013, 42, 7224.

30 K. Kirakci, P. Kubát, M. Kučeráková, V. Šícha, H. Gbelcová, P. Lovecká, P. Grznárová, T. Ruml, K. Lang, Inorganica Chim. Acta, 2016, 441, 42.

31 S. Anantharaj, S. R. Ede, K. Sakthikumar, K. Karthick, S. Mishra, S. Kundu, ACS Catal., 2016, 6, 8069.

32 M. Feliz, M. Puche, P. Atienzar, P. Concepción, S. Cordier, Y. Molard, ChemSusChem, 2016, 9, 1963. 
33 L. Chen, M. Wang, K. Han, P. Zhang, F. Gloaguen, L. Sun,

Energy Environ. Sci., 2013, 7, 329 ; J. P. Collin, A. Jouaiti, J. P. Sauvage, Inorg. Chem. 1988, 27, 1986. ;Y. Sun, J. P. Bigi, N. A. Piro, M. L. Tang, J. R. Long, C. J. Chang, J. Am. Chem. Soc., 2011, 133, 9212.; J. G. Kleingardner, B. Kandemir, K. L. Bren, J. Am. Chem. Soc. 2014, 136, 4.;B. Beyene, S. Mane, C.-H. Hung, Chem. Commun. 2015, 51, 15067;P. Zhang, M. Wang, Y. Yang, D. Zheng, K. Han, L. Sun, Chem. Commun. 2014, 50, 14153;J.-P. Cao, T. Fang, L.-Z. Fu, L.-L. Zhou, S.-Z. Zhan, Int. J. Hydrog. Energy, 2014, 39, 13972; P. Zhang, M. Wang, F. Gloaguen, L. Chen, F. Quentel, L. Sun, Chem. Commun. 2013, 49, 9455; M.-W. Chung, Y.-C. Liu, T.-H. Yen, M.-H. Chiang, ChemElectroChem 2018, 5, 20; F. Quentel, G. Passard, F. Gloaguen, Energy Environ. Sci. 2012, 5, 7757. 